\title{
FAST FASHION IN THE MOROCCAN APPAREL SuPPly ChaIn: A CASE STUdY
}

\author{
Abdelmounaim Aggour ${ }^{1}$, Abderrahmane Moussaid $^{1}$ and Ahmed Abou El Hassan ${ }^{2}$ \\ ${ }^{1} \mathrm{PhD}$ Student, Department of Economic Sciences, Hassan II University, Casablanca, \\ Morocco \\ ${ }^{2}$ Professor, Department of Economic Sciences, Hassan II University, Casablanca, \\ Morocco
}

\begin{abstract}
The apparel supply chain is a dynamic industry made distinctive by demand uncertainty and the handling of very many Stock Keeping Units (SKUs) during one season, which make it impossible to forecast demand accurately. Hence, apparel brands have to continuously maintain reactivity to the changing trends in consumer fashion tastes through quickly creating new designs that are suitable for all customers with affordable prices. In this context, fashion retailers adopting a new approach called fast fashion raised. In this paper, we will examine at first, from a literature review, the emergence of fast fashion model especially the ZARA Case. Then by conducting semi-structured interviews, we will analyze DIAMANTINE (a Moroccan fashion retailer brand) fast fashion model and identify the way of its success from a supply chain management perspective.
\end{abstract}

\section{KEYWORDS}

Fast Fashion; ZARA; DIAMANTINE; Moroccan apparel Supply Chain;

\section{INTRODUCTION}

Fast fashion is considered a key success factor for leading fashion brands. This concept, which is associated to other theories: Just in Time and Quick Response, can hardly be dissociated from the global fashion industry for it is regarded as a key success strategy for contemporary fashion retailers [1].

Fast fashion retailing is often referred to as fashion McDonaldization [2]. Fast fashion retailers have efficient and agile supplies allowing them to produce fashion items within 3 to 4 weeks, unlike traditional retailers that have a typical lead time of 9 months [3]. In addition, fast fashion items have affordable prices with a medium quality, a different concept from traditional system focusing on the quality of the items that can be carried for a long period [1]. Hereafter some main definitions of the fast fashion concept:

"Fast fashion is a business strategy which aims to reduce the processes involved in the buying cycle and lead times for getting new fashion product into stores, in order to satisfy consumer demand at its peak" [1]

"Various strategies to respond commercially to the latest fashion trends" Moore \& Fernie, Cited in [3]

“A marketing strategy responding to current fashion trends quickly by providing frequently updated fashion products" [4]

DOI: 10.5121/ijmvsc.2016.7402 
"The ability to track fashion trends quickly and to identify potentially popular new designs through daily proximity to fashion markets, fashion images and fashion makers" [5]

To gain a better understanding of fast fashion, it is important to understand how it differs from both the traditional and quick response systems. Thus, Cachon and Swinney classified production systems into four possible categories [6] (Figure 1):

- Traditional system: represents a conventional retailer with long lead times and a standard product design. This system is often called a push supply chain [7] where production is based on past sales. Therefore the average cycle time from design to production varies from 6 to 12 months and operations are inventory-based.

- Fast Fashion: a system that combines two other systems' capabilities:

- Quick Response: it's a pull supply chain system, based on information and it is customer-driven. A research program was initiated by Kurt Salomon Associates to develop procedures for the American domestic textile and apparel industry to become more competitive compared to imported products [8]. The research that has been undertaken as well as the improvement projects implemented have led to the development of QR methodologies.

- Enhanced Design: focuses on the design ability to motivate consumers' willingness-to-pay but ignores reduction of the production lead time.

\begin{tabular}{lcc}
\hline & Normal design & Enhanced design \\
\hline Slow production & Traditional $(T)$ & Enhanced design $(D)$ \\
Quick response & Quick response $(Q)$ & Fast fashion $(F)$ \\
\hline
\end{tabular}

Figure 1.The four possible production systems [6]

Thus, fast fashion retailers make lead time reduction occurs by completion of a part of product design, purchase of raw material and manufacturing of garments before the season starts. Then, they engage the remaining part during the season [9]. Instead, traditional retailers predict demand nine months before the season starts which makes the forecast less reliable [1]. So they finish product design and production before the season starts and they deliver them to stores during the season.

\section{ZARA CASE}

ZARA is a Spanish brand owned by INDITEX. It was established in 1975 and it has over than 2100 stores located in leading cities across 87 countries with almost 120000 employees. ZARA is the main development driver for INDITEX and plays a major role in increasing its share of sales in particular via ZARA's international activities [9].

In order to be reactive to the consumer demand during the season, ZARA began to invest in the production logistics, information technology, implementing Just in Time system, acquisition of a $130000 \mathrm{~m}^{2}$ warehouse near the headquarters in Arteixo and an advanced communication system to connect the headquarters to the buying center, production factories and stores [10]. 
The development of IT solutions (logistics, retailing, finance, merchandising...) continued during the 1990s and has been developed internally. This in-house software development is required by ZARA's specific needs [11]. Consequently, the business system that had resulted was particularly distinctive. ZARA manufactured its most fashion-sensitive products internally [9]. Unlike its rivals, more than $50 \%$ of ZARA's production is based in Europe [12].

In addition, ZARA success is explained by its agile supply chain efficiency [13][14]. ZARA's supply chain can be divided into four elements [9]: product design, sourcing and production, distribution \& retailing (Figure 2)

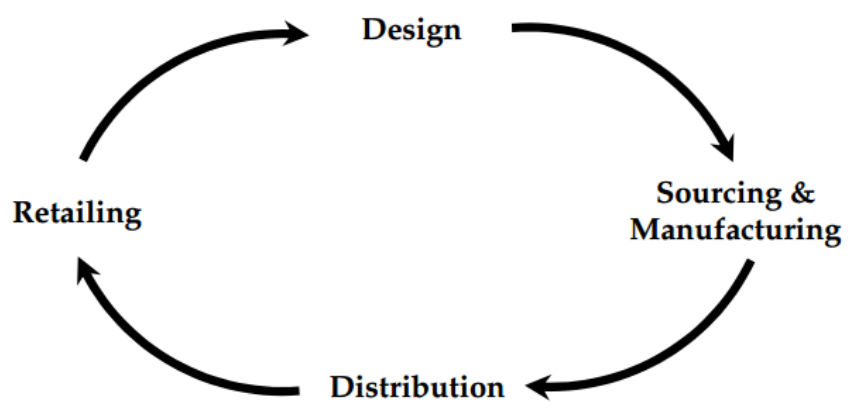

Figure 2.ZARA's business system [9]

\subsection{Product Design:}

The main task of the design team is not limited to product innovation, but also in reorganizing existing products elements and transforming them into new products [15]. In other words, ZARA's design team works not only on design of the upcoming season but also on the update of the current season designs. The design team comprises designers, market specialists and buyers who design almost 40000 items per year from which 10000 items are selected for production [16]. Designs are inspired from different sources: exhibitions, fairs, podiums, magazines [13].

\subsection{Sourcing and Manufacturing:}

ZARA purchases the fabric and other raw materials from external suppliers with the help of its buying centers (in Barcelona \& Hong Kong) and the buying team at the headquarters [9]. Key criteria for the buying decision are: required level of reactivity and expertise, effectiveness in terms of costs and the possession of sufficient production capacity [16]. COMDITEL, INDITEX's subsidiary, is in charge of the major part of fabric sourcing, dealing with more than 200 external suppliers.

ZARA produces half of its production in its own 22 Spanish small companies and uses subcontractors for sewing operations [13] [16]. The other half of production is made by external suppliers, 70\% of them are based in Europe (in particular Spain \& north of Portugal). From Asia, ZARA procures basic items because of costs advantages.

\subsection{Distribution:}

ZARA's system consists of an approximately $400000 \mathrm{~m}^{2}$ facility located in Arteixo and much smaller satellite centers in Argentina, Brazil, and Mexico that consolidated shipments from Arteixo [9]. The finished clothes, after being packed and inspected in quality, are sent to distribution center through underground conveying belt [16]. 
Operating hours follow the weekly rhythm of the orders. In a normal week, the warehouse functions around the clock for four days but runs for only one or two shifts on the remaining three days. Ordinarily, 1200 people fill the orders, each within eight hours. But during peak seasons, the company adds as many as 400 temporary workers to maintain lead times [16]. Shipments from the warehouse are made twice a week to each store via third-party (3PL) delivery services, with shipments two days a week to one part of the store network and two days a week to the other [9].

Distributions are carried out according to orders from each store; goods are ready for delivery 8 hours upon receipt of orders [15]. Shipments reach most European stores in 24 hours, U.S. stores in 48 hours, and Japanese shops in 72 hours [9].

\subsection{Retailing:}

ZARA tries to localize its stores in the most refined, prestigious and overcrowded places [16]. It runs three independent product lines: women, men, and children. Each product line is managed by a separate team of regional managers, commercials and designers. Also, the three product lines are managed by three independent section managers at each store. Each section manager has a team of sales people and cashiers; the women's section manager is also the overall store manager [10].

The stores varies greatly in size and layout but an average store is $1200 \mathrm{~m}^{2}$ in size and carries about 40,000 units of inventory [8]. ZARA put a lot of emphasis on creating attractive interior designs that conveys freedom and quiet comfort to the customer but also on ensuring that shelves and store windows are similarly presented in all ZARA stores [10].

Sales data are sent from ZARA's stores to the head office on a daily basis and replenishment orders are made twice a week in accordance with the available inventory and sales situation [15].

\section{Methodology}

Fast fashion has received little attention in academic research, and as a concept, it was felt there was widespread misunderstanding of the nature of fast fashion in relation to the supply chain [1]. To better understand the concept of fast fashion in the Moroccan apparel supply chain, our research is based on an exploratory single case study method. According to [17], the single case study, such as multiple case studies can be generalized to theoretical propositions and not to people and universe other than the case. A theory is true until it has been shown to be false; the value of the theoretical contributions of case studies cannot be questioned [18]. The purpose of an exploratory study is to gather as much information as possible about a phenomenon that is little understood in order to establish a basis for further research [19].

The technique used for gathering data is qualitative: in-depth interviews. Key informants selected belong to the DIAMANTINE's internal supply chain. A total of 8 in-depth structured interviews with key informants from each stage of the company internal supply chain were undertaken, including: designer, product manager, quality control, finished goods reception, delivery coordinator, data analyst and merchandising manager.

All interviews were recorded after verbal agreement of respondents. Agreement was collected at the beginning of each interview. The interviews were transcribed and analysed using the content analysis approach. 


\section{MOROCCAN FAST FASHION MODEL: DIAMANTINE CASE}

DIAMANTINE is a Moroccan fashion retailer brand. A subsidiary of SOFT Group, it was founded in 2002. This Moroccan brand has evolved to become the symbol of Moroccan sparkling and easy going fashion. Its collections are inspired from the Moroccan tradition and the latest fashion trends with excellent level of quality and affordable prices. DIAMANTINE is amongst fashion retailers that have their own distribution networks in Morocco, Algeria and UAE. While combining tradition and modernity, DIAMANTINE, which represents Moroccan culture, symbolizes elegance and creativity through its products.

To better meet customers' needs, the brand manages three different lines:

- DIAMANTINE Man: a man line ready-to-wear with a Moroccan touch, classy and modern.

- Diam'Kids by DIAMANTINE: playful models for children inspired from Moroccan tradition.

- DIAMANTINE Woman: a refined and unique style for a trendier clientele keen on fashion, originality and elegance.

DIAMANTINE network employs 300 people in Morocco and a hundred internationally. It operates with 80 stores inside Morocco and 20 stores abroad, all directly-operated stores. The brand will create new franchises in several countries including Kuwait, Qatar, France, and Belgium.

The Analysis of the semi-structured interviews data drove to form the DIAMANTINE's supply chain (Figure 3).

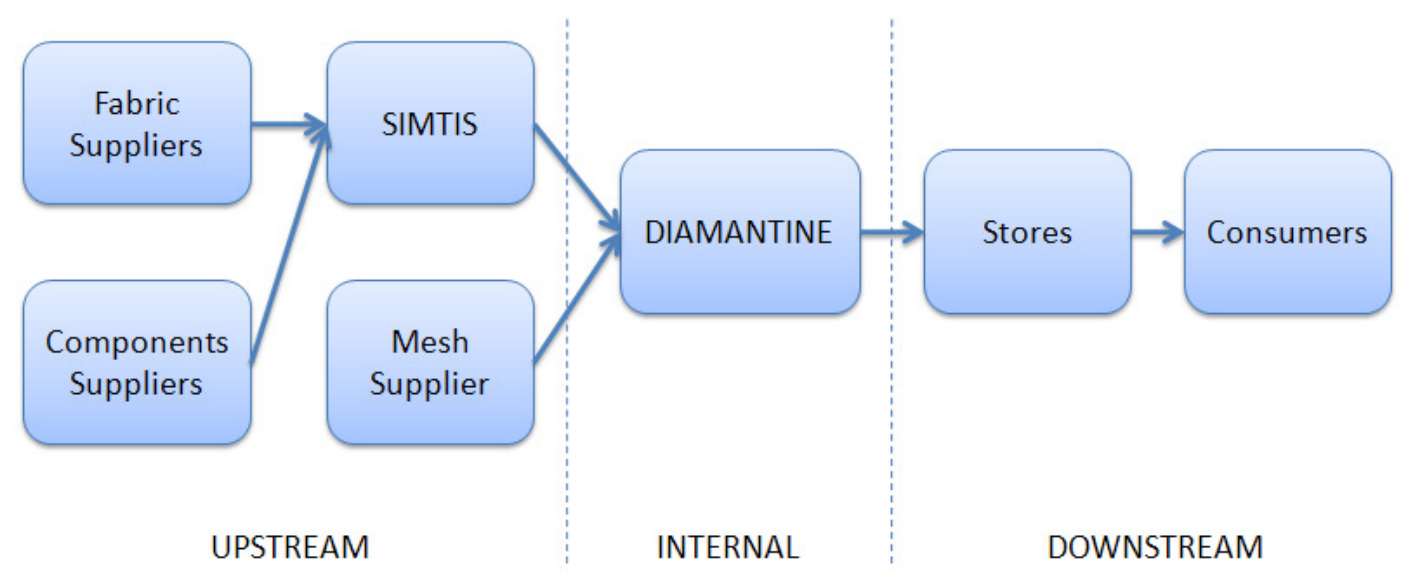

Figure 3.DIAMANTINE's simplified Supply Chain

\subsection{Product design}

DIAMANTINE designs its garments a year before the season starts and they are made for two seasons Autumn/Winter and Spring/Summer. Based on a database (patterns, images, etc.), the design process starts by defining themes to be launched. The themes are inspired primarily from the Internet and exhibitions and they are launched at a frequency of one theme per month.

Once the sketches are available, weekly selection sessions are organized by a committee consisting of area manager, designer, product manager, purchasing manager and the general manager. The objective of these sessions is to select, from the sketches created by the designer, the models to go into production and those to cancel. 


\subsection{Sourcing and Manufacturing}

In parallel with the design sketches, product manager provides a collection plan based on projected sales objectives. This plan consists of: the number of models to be launched, the average quantities by reference/family and the average prices. Then, a panel is established containing detailed required raw materials to be used in the selected models. Finally, sums of materials and supplies required are made and the purchase orders are established.

SIMTIS, a SOFT Group subsidiary, handles fabric sourcing and other components for DIAMANTINE which only intervenes in selecting the fabric to be purchased and the target prices. SIMTIS is also the main supplier of garments. DIAMANTINE benefits from SIMTIS reactivity since they belong to the same Group and SIMTIS factory is installed nearby DIAMANTINE's logistics platform.

Once garments are available, SIMTIS sends notification for delivery including the quantity to be delivered. These deliveries are made following a monthly delivery plan set before the season starts. Arrivals to the logistics platform are made Tuesdays and Thursdays. The garments are received ready for sale and contain the price tags and the barcode labels.

The logistics coordinator controls a quality sheet signed by the quality controller and no reception can be accepted without written approval. In fact, to maintain reactivity of the process, the quality controller checks garments compliance at the supplier place. Finally, the receipt coordinator enters the garments received by model, colour and size in the information system.

\subsection{Distribution}

DIAMANTINE has a logistics platform based on Casablanca and all garments from different suppliers, for the local market and for export, pass through this logistics platform. The platform operates in one shift ( 8 hours) with a team dedicated to dispatching deliveries to stores.

The delivery coordinator performs garments dispatching by model, colour and size using software application developed internally. The quantity allocations are defined based on the stores turnover, the stores location and the price category of the garments. Orders picking is done from Monday to Wednesday and deliveries are made on Thursdays and Fridays.

For stores located in Casablanca and Mohammedia (town located nearby Casablanca), DIAMANTINE uses its own means of transportation. However and for the rest of Morocco, it uses a 3PL delivery services. Deliveries for stores located in Casablanca and Mohammedia are made the same day and the lead time for those located in other Moroccan cities is between 12-24 hours. Delivery lead time for stores located abroad is up to one week.

In case of shortage of a bestseller garment, the delivery coordinator operates inter-stores transfers. Stores are replenished from the inventory of other stores where the requested item is unsold. On arrival of the garments at the store, the store manager validates the delivery on the information system (IS).

\subsection{Retailing}

At the entrance of DIAMANTINE stores, there are different color atmospheres and not just one or two colors. This technique, used at the stores, aims to increase profitability of the store and to facilitate the products sales by a continuous adaptation of assortment to customers' needs and by an appropriate garments display. 
The store team is formed of one store manager, sales assistants and cashiers. Their number depends on the size of the store and its turnover. In parallel with the landscaping projects of a new store opening, there is a team that has been already recruited and is taking a training program at another store. This team will be assigned to the new store with experienced people in particular the store manager.

Once the team is in place, it first performs counting of the received garments, then it smoothes them, exposes them in hangers, shelves and windows and finally the store manager enters the received quantities in the IS.

When a new collection comes in, the former one is advanced at the back of the store and the new collection is displayed at the entrance. At the beginning of each season, more importance is given to the new collection. However, during the clearance period, more importance is given to the old collection.

Every 15 days, items displayed on the store's windows are changed. The merchandising manager put the new collection together in a "test store" located at the headquarters. This enables the merchandising manager to find the best combinations for the displayed garments. Then, photos of shelves and windows display are taken and sent to store managers that can choose amongst four or six different themes to display them in their stores. The windows display change gives the chance to some hidden garments inside the store to be exposed and then to be sold.

\subsection{Information sharing}

DIAMANTINE supply chain is information-driven. Supply chain members share information such as sales data and customers' feedback.

SIMTIS communicates the delivery schedule of garments with the quantities to be delivered to DIAMANTINE and they discuss the progress of delivery on a weekly basis. SIMTIS also communicates inventory levels by model to DIAMANTINE.

The merchandising manager uses social media networking to share new shop mannequin layout with stores managers. The latter communicate feedback on each collection to the data analyst. At the end of the season, data analyst makes a synthesis of all themes. In addition, Data analyst receives qualitative data related to displayed garments from area managers. Based on these data, analysis are made and shared with top management.

The store managers use phone to communicate with their customers. DIAMANTINE uses also social media networks to communicate with customers. Sending SMS to customers is another form of communication that was used. To get its customers feedback, DIAMANTINE uses a mini-questionnaire at the stores that they fill out and place in a dedicated box. These miniquestionnaires are then sent to headquarters for customer feedback analysis.

\section{CONClusion}

The aim of this paper was, from one hand, to give a better understanding of the fast fashion model from a supply chain perspective and from the other hand to understand how far DIAMANTINE (as a Moroccan fashion retailer brand) is practicing fast fashion best practices through its supply chain.

ZARA's case has been studied for being the pioneer in fast fashion industry nowadays. ZARA has a responsive supply chain and highest profit margins that are the envy of the industry. 
DIAMANTINE, a Moroccan fashion retailer brand, is trying to 'borrow' ZARA's business model. DIAMANTINE has succeeded in some aspects such as reactivity to customer feedback, continuous introduction of new styles during the season and using information system to track sales data. In addition, and unlike ZARA, DIAMANTINE has developed a good relationship with its customers. In fact at DIAMANTINE, a store manager could call usual customers to inform them for new arrivals. However, the brand lacks some practices where ZARA excels such as developing product, forecasting and planning jointly with the suppliers, ordering finished goods in small batches and making small deliveries to stores.

\section{REFERENCES}

[1] Barnes, L., Lea-Greenwood, G., (2006) "Fast Fashioning the supply chain: shaping the research agenda", Journal of Fashion Marketing and Management, Vol. 10 No. 3, pp. 259-271.

[2] Ritzer, G., (2008) “The McDonaldization of society”, Los Angeles, CA: Pine Forge Press.

[3] Jin, B., Chang, H. J., Matews, D. R., Gupta, M., (2012) "Fast Fashion Business Model: What, Why and How?" , Fashion supply chain management: Industry and business analysis, pp. 193-211, Business Science Reference.

[4] Byun, S. E., Sternquist, B., (2008) "The antecedents of in-store hoarding: Measurement and application in the fast fashion retail environment", International Review of Retail, Distribution and Consumer Research, Vol. 18 No. 2, pp. 133-147.

[5] Doeringer, P., Crean, S., (2004), Can fast fashion save the US apparel industry? , Working Paper. Cambridge, MA: Harvard University Centre for Textile \& Apparel Research.

[6] Cachon, P., Swinney, R., (2011) "The value of fast fashion: Quick response, enhanced design, and strategic consumer behavior", Management Science, Vol. 57, No. 4, pp. 778-795.

[7] Levy, M., Weitz, B. A., (2007) "Retailing management", 6th edition, Boston, MA: McGraw-Hill Irwin.

[8] Lowson B., King, R., Hunter, A., "Quick Response: Managing the Supply Chain to Meet Consumer Demand”, John Wiley and Sons, 1999

[9] Ghemawat, P., Nueno, J. L., (2006) “ZARA: Fast fashion”, Boston, MA: Harvard Business School Publishing.

[10] Ton, Z., Corsi, E., Dessain, V., (2010) "ZARA: Managing stores for fast fashion", Harvard Business School Publishing, 9-610-042.

[11] Mcafee, A., Dessain, V., Sjoman, A., (2007) “ZARA: IT for fast fashion", Harvard Business School Publishing, 9-604-081.

[12] Bruce, M., Daly, L., (2006) "Buyer behaviour for fast fashion”, Journal of Fashion Marketing and Management: An International Journal, Vol., 10 No. 3, pp. 329 - 344.

[13] Dutta, D., (2002) "Retail at the speed of fashion", Third Eye Sight.

[14] Sull, D., Turconi, S., (2008) "Fast Fashion lessons", London Business School Review.

[15] Zhang, Q., (2008) “Analysis on the Successful Case of Efficient Supply Chain in ZARA”, IEEE, 978-1-4244-2108-4.

[16] Ferdows, K., Lewis, M. A., Machuca, J. A. D, (2003) “ZARA”, Supply Chain Forum, Vol. 4, No. 2, pp. 62-67.

[17] Yin, R., K., (2003) "Case study Research: Design and methods", 3 rd edition, Applied Social Research Methods Series, Vol. 5, Sage Publications.

[18] Popper, K., (2002) "The logic of scientific discovery", Routledge Classics. ISBN 0-203-99462-0.

[19] Ghauri, P. N., Gronhaug K., (2002) "Research Methods in Business Studies: A Practical Guide", Financial

Times,

Prentice

Hall. 